\title{
Development of Long-Lifetime Pulsed Gas Valves for Pulsed Electric Thrusters
}

\author{
Wendel M. Burkhardt, John M. Crapuchettes \\ WASK Engineering, Inc., Cameron Park, CA 95682 \\ Brad M. Addona, Kurt A. Polzin* \\ NASA-Marshall Space Flight Center, Huntsville, AL 35812
}

\begin{abstract}
I. Abstract
$\mathrm{I}$ is advantageous for gas-fed pulsed electric thrusters to employ pulsed valves so propellant is only flowing to the device during operation. The propellant utilization of the thruster will be maximized when all the gas injected into the thruster is acted upon by the fields produced by the electrical pulse. Gas that is injected too early will diffuse away from the thruster before the electrical pulse can act to accelerate the propellant. Gas that is injected too late will miss being accelerated by the already-completed electrical pulse. As a consequence, the valve must open quickly and close equally quickly, only remaining open for a short duration. In addition, the valve must have only a small amount of volume between the sealing body and the thruster so the front and back ends of the pulse are as coincident as possible with the valve cycling, with very little latent propellant remaining in the feed lines after the valve is closed. For a real mission of interest, a pulsed thruster can be expected to pulse at least $10^{10}-10^{11}$ times, ${ }^{1}$ setting the range for the number of times a valve must open and close.

The valves described in this paper have been fabricated and tested for operation in an inductive pulsed plasma thruster (IPPT) for in-space propulsion. ${ }^{2}$ In general, an IPPT is an electrodeless space propulsion device where a capacitor is charged to an initial voltage and then discharged, producing a high-current pulse through a coil. ${ }^{3}$ The field produced by this pulse ionizes propellant, inductively driving current in a plasma located near the face of the coil. Once the plasma is formed, it can be accelerated and expelled at a high exhaust velocity by the electromagnetic Lorentz body force arising from the interaction of the induced plasma current and the magnetic field produced by the current in the coil.

The valve characteristics needed for the IPPT application require a fast-acting valve capable of a minimum of $10^{10}$ valve actuation cycles. Since even $10^{9}$ cycles is well above anything demonstrated, this lower value was selected as the design point for the present work. The valve seal must remain leak-tight throughout operation, and the body must maintain a low internal leakage at relatively high operating temperatures. The full set of design requirements used for this program are summarized in Table 1.

In this work, we describe two pulsed gas valves that have been fabricated to have long lifetime and demonstrate the characteristics listed above. The first is a miniaturized, conventional electromagnet-based valve while the second is a piezoelectric-based valve design.

The conventional valve, shown in Fig. 1, is opened by use of a solenoid electromagnetic actuator. When current is applied to the solenoid coil, magnetic forces pull the plunger away from the valve seat, allowing fluid to flow through the valve. Removal of electrical current permits the spring and fluid pressure to seat the plunger, halting the flow of fluid. The valve body is fabricated from 304L corrosion resistant steel (CRES) and while the parts that form the magnetic circuit are fabricated from 430 CRES. This material does not have optimum magnetic properties, but its corrosion resistance permits incorporation into a design without requiring an additional plating process. A viton O-ring compound (Parker V0884-75), selected for its mechanical strength at elevated temperatures, was used for the valve seat seal. The design was based solely on the use of analytical sizing calculations, as opposed to a more rigorous
\end{abstract}

\footnotetext{
*Propulsion Research Engineer, Propulsion Research and Technology Applications Branch, Propulsion Systems Department. Associate Fellow
} AIAA. 
Table 1. Long-lifetime pulsed valve design requirements.

\begin{tabular}{l|l}
\hline \hline Parameter & Requirement \\
\hline Flow rate & $\begin{array}{l}\geq 164 \mathrm{sccm}(10 \mathrm{scim}) \mathrm{GAr} \text { at } 276 \mathrm{kPa}(40 \mathrm{psid}) \text { inlet } \\
\text { pressure, } 0 \mathrm{kPa}(0 \mathrm{psia}) \text { outlet pressure, and } 21{ }^{\circ} \mathrm{C}\left(70^{\circ} \mathrm{F}\right)\end{array}$ \\
\hline $\begin{array}{l}\text { Opening and closing } \\
\text { response }\end{array}$ & $\leq 1 \mathrm{~ms}$ at $103-690 \mathrm{kPa}(15-100 \mathrm{psid})$ and \\
& $21-149^{\circ} \mathrm{C}\left(70-300{ }^{\circ} \mathrm{F}\right)$ \\
\hline Internal leakage & $\leq 1 \times 10^{-3} \mathrm{sccs} \mathrm{GHe}$ at $103-690 \mathrm{kPa}(15-100 \mathrm{psid})$ \\
& and $21-149^{\circ} \mathrm{C}\left(70-300{ }^{\circ} \mathrm{F}\right)$ \\
\hline Lifecycle & $>10^{9} \mathrm{cycles}$ \\
\hline Operating temperature & up to $149^{\circ} \mathrm{C}\left(300{ }^{\circ} \mathrm{F}\right)$ \\
\hline \hline
\end{tabular}

finite element analysis. While this valve is small and relatively lightweight, it does not represent a design that is optimized for mass and/or a given volume envelope.

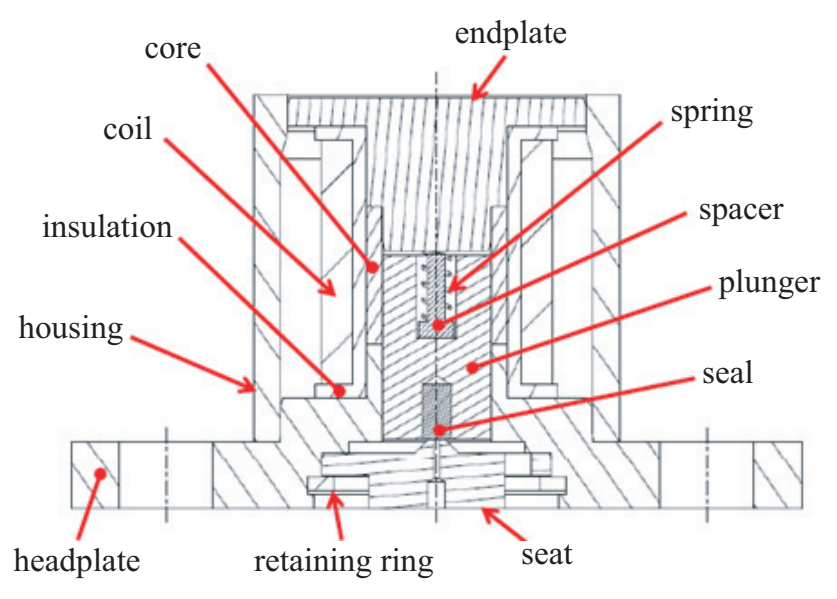

Figure 1. Cross-sectional view of the interior of the solenoid-based pulsed gas valve.

The piezoelectric valve is a "puller" valve design. Applying a voltage to the piezo crystal causes it to elongate and pull a pintle off the seat, opening the valve. The valve seal consists of the pintle with an external, spherically-formed tip fabricated from Inconel 625 and the seat fabricated from Inconel 718 and possessing a spherical surface that permits the pintle to align with the valve body centerline after each cycle, maintaining the circumferential metal-on-metal seal. The contact stress on the valve pintle is expected in the worst case to be $96.5 \mathrm{MPa}$ (14 ksi), which is well below the work hardening value of 413.7 MPa (60 ksi) for Inconel 615.

Results presented in this work will compare the performance of each valve, both to each other and to the valve design requirements given in Table 1. In general, both valves meet all the performance envelope requirements, but the piezoelectric valve consumes considerably less power and has a faster response time over the conventional solenoiddriven valves.

\section{Acknowledgments}

This work was partially funded through the In-Space Propulsion Project of the Game-Changing Development (GCD) Program of NASA's Office of the Chief Technologist and through a 2014 NASA Phase 1 SBIR under contract number NNX14CM33P. 


\section{References}

${ }^{1}$ R.H. Frisbee, "Evaluation of High-Power Solar Electric Propulsion Using Advanced Ion, Hall, MPD, and PIT Thrusters for Lunar and Mars Cargo Missions," 42nd AIAA/ASME/SAE/ASEE Joint Propulsion Conference, Sacramento, CA, July 9-12, 2006. AIAA Paper $2006-4465$.

${ }^{2}$ A.K. Martin, R.H. Eskridge, A. Dominguez, K.A. Polzin, D.P. Riley, and A.C. Kimberlin, "Design and Testing of a Small Inductive Pulsed Plasma Thruster," 34th International Electric Propulsion Conference, Kobe, Japan, July 4-10, 2015.

${ }^{3}$ K.A. Polzin, "Comprehensive Review of Planar Pulsed Inductive Plasma Thruster Research and Technology," J. Propuls. Power vol. 27, No. 3, pp. 513-531 (2011). 